\title{
LAS ZONAS DE EMPLEO Y DESARROLLO ECONÓMICO (ZEDE), $Y$ EL PERFECCIONAMIENTO DE LOS MECANISMOS DE DESPOJO EN HONDURAS
}

\section{ZONES FOR EMPLOYMENT AND ECONOMIC DEVELOPMENT (ZEDE), AND THE IMPROVEMENT OF DISPOSSESSION MECHANISMS IN HONDURAS}

\section{Daniel Torres Sandí*}

\section{RESUMEN}

En este artículo se reflexiona sobre las implicaciones de las Zonas de Empleo y Desarrollo Económico (ZEDE), considerando la relación que su marco legal plantea, frente a la institucionalidad hondureña. A través de revisión de documentación oficial, abordajes periodísti$\cos y$ relatos de organizaciones de derechos humanos, se identifica que el proyecto avanza de forma sostenida, a pesar de existir cuestionamientos sobre su financiamiento, implicaciones legales y sus efectos sobre la población nativa del Caribe hondureño.

PALABRAS CLAVE: HONDURAS * ESTADO * GOBERNABILIDAD * DESARROLLO REGIONAL * EMPLEO

\section{ABSTRACT}

This article aims to assess the implications surrounding the Zones for Employment and Economic Development (ZEDE), considering how its legal framework stands in front of Honduran institutions. Through the review of Honduran journals, official documentation, and statements from Human Rights organizations, we conclude that the project is steadily ongoing, despite widespread objections about its funding, legal implications, and posible effects on native population of the Honduras' Caribbean shore.

KEYWORDS: HONDURAS * STATE * GOVERNANCE * REGIONAL DEVELOPMENT * EMPLOYMENT

Estudiante de Licenciatura en Sociología, Universidad de Costa Rica, Costa Rica.

daniel.torressandi@ucr.ac.cr 


\section{1) INTRODUCCIÓN}

El sociólogo mexicano Rodolfo Stavenhagen publicó en 1965 sus famosas Siete tesis equivocadas sobre América Latina, texto que se consolidó como pieza clave y sintética de los aportes de la sociología latinoamericana para la comprensión del devenir regional en la segunda mitad del siglo xx. Cinco décadas después, el profesor Sergio Villena (2017) postuló una ampliación de dichas tesis, poniendo sobre la mesa una octava, la cual indicaría que "el Estado es, en ausencia de una burguesía nacional pujante, el principal agente de desarrollo y de integración nacional" (p.14). Lo interesante para este artículo radica en la refutación que paralelamente se le adjunta a dicha tesis:

Asimismo, podemos postular, como crítica a esa tesis, desde la perspectiva de los debates del colonialismo interno, la siguiente: el Estado es menos un instrumento de desarrollo e integración que de sometimiento y explotación, ya que ha sido, a lo largo de la historia, el principal instrumento que ha utilizado el grupo étnico dominante para mantener y profundizar el colonialismo interno (Villena, 2017, p.13).

El concepto de colonialismo interno ha postulado que a lo interior de los Estados se generan dinámicas de conquista y despojo, similares a las existentes en los procesos de conquista imperial frente a potencias extranjeras. Honduras vivió a través de su historia estos procesos, consolidándose como pieza clave de la explotación bananera bajo modalidad de enclave durante el siglo xx (Laínez y Meza, 1973). En el panorama hondureño reciente, numerosos son los ejemplos que ilustran el nivel de enquistamiento de las redes de corrupción y desfal$\mathrm{co}^{1}$; se denota que en el panorama posgolpe de Estado, se ha consolidado como ganadora una camarilla de políticos y empresarios, que logró afianzar extraordinariamente su control sobre

1 Resulta representativo el desfalco al Instituto Hondureño de Seguridad Social o el caso Rosenthal, por citar apenas dos. el poder estatal distorsionado (Waxenecker, 2016). En general, el escenario sociopolítico hondureño se caracteriza por la transversalidad con que operan redes indebidas de poder y estructuras parapolíticas orientadas al resguardo de formas ilícitas de acumulación, así como, su subsecuente y necesaria impunidad (ídem).

$\mathrm{Al}$ ser Centroamérica un territorio con tanta riqueza natural, la colusión de élites transnacionales con actores estatales locales ha tenido como uno de sus principales propósitos el progresivo acaparamiento de dichos recursos (Robinson, 2012). La reconfiguración de las élites hondureñas ha transitado desde el modelo agroexportador hacia la emergencia de un Nuevo Modelo Económico (Sosa, 2017). En este último, las élites han aumentado considerablemente su riqueza, gracias al diseño de un Estado pro-empresarial cuestionablemente inclinado a favorecer intereses particulares, por encima del beneficio público.

Núñez et al. (s.f.) postulan que las pretensiones de desarrollo han sido encarnadas por el Estado hondureño a través de la profundización del extractivismo por la vía de proyectos y marcos normativos que han configurado sofisticados mecanismos de despojo y traslación de bienes naturales de propiedad comunitaria, hacia la acumulación económica en arcas privadas, $y$ muchas veces extranjeras. Lo anterior no solo con la omisión, sino también con la activa participación de entidades estatales $y$ funcionarios públicos. Informes de investigación, tales como Honduras: el país más peligroso del mundo para el activismo ambiental, publicado por la ONG Global Witness (2017), han expuesto los hilos que conectan a importantes personalidades del Partido Nacional de Honduras - actualmente gobernante- con proyectos de carácter extractivista pertenecientes a grandes consorcios y grupos empresariales.

En resumen, siguiendo a Barahona (2018), Honduras se ha convertido en un caso insigne en cuanto a la colusión de intereses privados y corporativos, con el accionar del Estado. Si bien, esto se presenta en muchos países latinoamericanos, en este artículo se estudian las Zonas de Empleo y Desarrollo Económico (en adelante, ZEDE), con el propósito de postular 
que actualmente el Estado hondureño se posiciona en la vanguardia regional, con respecto a la innovación en cuanto a estrategias de despojo y pérdida de soberanía frente a intereses privados. Se postula que hay insumos para interpretar que el Estado hondureño podría estar dispuesto a ver reducido su papel como nicho de acumulación y convertirse en un medio tangencial de acumulación, que progresivamente traslada sus dispositivos de aprehensión de recursos y riqueza hacia el dominio privado legítimo.

Se inicia abordando aspectos conceptuales sobre la noción de ciudad modelo y sus diferencias con el concepto de Zona Económica Especial. En segunda instancia, se revisa el transcurrir del proyecto de las ZEDE en el Estado hondureño, así como, los principales elementos de su armazón jurídico ${ }^{2}$. Por último, se presta atención a las posibilidades de financiamiento del Banco Interamericano de Desarrollo (BID) de cara a las primeras andanzas del proyecto, así como, sus posibles implicaciones sociales, especialmente sobre el pueblo garífuna de la costa Caribe.

\section{2) EL PLANTEAMIENTO CONCEPTUAL ALREDEDOR DE LAS “CIUDADES MODELO"}

Antes de profundizar en el caso hondureño, es relevante revisar la discusión alrededor de una idea que no es nueva, y que reviste cierto grado de confusión y ambigüedad que debe ser atendido. En primer lugar, es menester distinguir el concepto de ciudad modelo - o en inglés charter city - con el de Zonas Económicas Especiales (ZEE) —Special Economic Zones (SEZ) - Estas segundas, si bien, brindan ciertos grados de cesión en materia fiscal y productiva, no incursionan a profundidad en términos de autonomía y autocontrol político-administrativo territorial. Arias et al. (2016) explican que hay dos enfoques principales en cuanto a la definición del concepto de las Zonas Económicas Especiales. El primero, basado en sus características, lo cual implica atender que estas zonas se crean cuando un

2 Véase Decreto Legislativo nro. 120-2013 del Congreso Nacional de Honduras. país decide establecer ciertas condiciones preferenciales para determinada circunscripción territorial, tales como, exenciones aduaneras, servicios públicos y condiciones preferenciales, cuyo propósito radica en atraer inversiones extranjeras (Dixin, 1981).

$\mathrm{El}$ otro enfoque encuadra a las ZEE en un ámbito más complejo del desarrollo territorial. Dentro de esta perspectiva, Tuz (2011, como citado en Arias et al., 2016) quien define a las ZEE como:

... un espacio del territorio nacional delimitado por el Estado, en el que, con inversión pública $y / 0$ privada, se impulsa el desarrollo de actividades ligadas a la transferencia de tecnología, innovación, provisión de servicios logísticos especializados y transformación industrial, a través del establecimiento de incentivos especializados condicionados a cumplimiento de objetivos específicos de inversiones nuevas, orientados a la generación de empleo de calidad, desarrollo territorial $y$ transferencia tecnológica (pp. 86-87).

En resumen, las Zonas Económicas Especiales comprenden un amplio rango de áreas espacialmente definidas que combinan distintos esquemas de política pública e infraestructura, orientadas a la promoción de la inversión y la exportación. Por ende, en las zze se mantiene en plena vigencia la competencia de los poderes estatales, $y$ la finalidad se restringe al establecimiento de un entorno con las mejores condiciones posibles para la acumulación por parte del sector privado.

En la misma línea de maximización de la acumulación pero trascendiendo las simples facilidades tributarias y productivas, se ubica el concepto de ciudades modelo. Aquí se complejiza radicalmente la finalidad de "promover el crecimiento económico", para adscribirse a una pretensión orientada hacia una supuesta regeneración y transformación de la totalidad de las estructuras sociopolíticas, administrativas $y$ legales que, en mayor o menor nivel, están usualmente cubiertas bajo el manto del Estadonación. En el cuadro 1, se resumen algunas diferencias entre los conceptos de Zona Económica Especial y Ciudad Modelo. 


\section{CUADRO 1 \\ DIFERENCIACIONES BÁSICAS ENTRE LOS CONCEPTOS DE ZONA ECONÓMICA ESPECIAL Y CIUDAD MODELO}

\begin{tabular}{l|l|l}
\hline & ZONAS ECONÓMICAS ESPECIALES & CIUDADES MODELO \\
\hline Origen histórico & $\begin{array}{l}\text { La primera fue establecida en Shannon, Irlanda, } \\
\text { en 1959. No obstante, la idea tomó mayor } \\
\text { impulso a partir de 1980, cuando se estableció } \\
\text { la primera zEE en China, específicamente en } \\
\text { Shenzhen. }\end{array}$ & $\begin{array}{l}\text { Romer (27 de enero de 2010) ha mencionado } \\
\text { Hong Kong como un exitoso ejemplo del } \\
\text { modelo de las ciudades modelo. No obstante, } \\
\text { existe amplia polémica al respecto }\end{array}$ \\
\hline $\begin{array}{l}\text { Marco y } \\
\text { aplicación } \\
\text { jurídica }\end{array}$ & $\begin{array}{l}\text { Plena vigencia de la normativa nacional. } \\
\text { Régimen regulatorio especial establecido por el } \\
\text { gobierno. }\end{array}$ & $\begin{array}{l}\text { Suerte de "isla jurídica". Estatuto acordado } \\
\text { entre uno o varios países "desarrollados", y } \\
\text { el país donde se afincará la ciudad modelo. } \\
\text { Aplicación de justicia en cortes extranjeras. }\end{array}$ \\
\hline $\begin{array}{l}\text { Política Fiscal } \\
\text { Ejercicio de la } \\
\text { fuerza legítima }\end{array}$ & $\begin{array}{l}\text { Incentivos de índole tributaria. Facilidades } \\
\text { aduaneras. }\end{array}$ & $\begin{array}{l}\text { Definida por el estatuto, pero adscrita la lógica } \\
\text { del libre comercio. }\end{array}$ \\
\hline $\begin{array}{l}\text { Propósito genentencia excepción en cuanto a } \\
\text { estructural }\end{array}$ & $\begin{array}{l}\text { Atracción de inversión extranjera directa y } \\
\text { tecnología. Dinamización económica. Aumento } \\
\text { de exportaciones. }\end{array}$ & $\begin{array}{l}\text { Usualmente se establece a través del } \\
\text { estatuto, la propia constitución, regulación y } \\
\text { administración de la policía local }\end{array}$ \\
\hline
\end{tabular}

Fuente: $\quad$ Elaboración propia con base en el Instituto Centroamericano de Estudios Fiscales (2018), Romer (27 de enero de 2010 y 3 de marzo de 2010).

Paul Romer - ganador del Nobel de Economía en 2018 - , ha sido uno de los principales promotores del concepto de ciudades modelo. En años recientes, sus principales aportes han girado en torno a posicionar la innovación $y$ el conocimiento como factores determinantes para garantizar un aumento cualitativo de los factores productivos. Su producción conceptual más resonada ha sido la teoría del crecimiento endógeno, la cual descansa sobre tres premisas fundamentales. La primera indica que el núcleo del crecimiento económico se encuentra en el "cambio tecnológico", el cual se entiende como la generación de nuevas ideas y técnicas para transformar y sofisticar los procesos productivos. La segunda postula el carácter endógeno de ese proceso, en tanto que los incentivos de mercado serían los principales motores para

$3 \quad$ Ver kee-cheok $y$ kim-leng (2013).

4 Ver fernández (14 de julio de 2012). la generación de tales avances tecnológicos. El esquema se cierra con la tercera premisa, la cual indica que una vez inventados estos conjuntos de nuevas ideas o técnicas, pueden ser utilizadas una $y$ otra vez sin costos adicionales (Romer, 1990).

Profundizar sobre lo propuesto por Romer escapa del alcance del presente artículo; sin embargo, sí es necesario reflexionar en cuanto a lo directamente vinculado con la fundamentación teórica y justificación de las ciudades modelo. En su ensayo Technologies, Rules, and Progress: The Case for Charter Cities, posiciona a las ciudades modelo como una forma de configurar nuevas reglas sociopolíticas y acuerdos institucionales, que permitan el cambio tecnológico y el surgimiento de nuevas ideas. Romer (3 de marzo de 2010) argumenta que estas reglas y acuerdos, son requeridos para hacer posibles las diversas interacciones sociales que el "cambio tecnológico" requiere. En este punto, es esencial sopesar 
cuáles serían estas supuestas reglas estrictamente requeridas por el "cambio tecnológico", para poder ser el "motor del desarrollo" de un país como Honduras.

A partir de lo conceptualizado sobre las ciudades modelo, se desprende que su componente central radica en el nivel de autonomía que posean. Siguiendo lo señalado por Sagar (2016), una ciudad modelo es una entidad autogobernada, cuyos niveles de autonomía deben estar definidos $y$ deben trascender el plano estrictamente tributario o económico, para abarcar la esfera de la determinación administrativa, la aplicación de la justicia, el ejercicio legítimo de la fuerza, entre otros. Se debe aclarar que el componente tributario no tiene menor importancia en una ciudad modelo que en una ZEE; claramente ambos conceptos plantean un distanciamiento de la política tributaria que rige en el resto del Estado-nación, lo cual pretende mayor liberalización comercial. La diferencia nuclear radica en que la mayor cuota de autonomía que ostentan las ciudades modelo, les permite establecer de forma discrecional su propia política tributaria, a diferencia de las ZEE, en las cuales, si bien hay incentivos tributarios, estas continúan emanando desde el poder estatal.

Entonces, siguiendo la narrativa de Romer (3 de marzo de 2010), el eje central de las ciudades modelo radica en poseer tal nivel de autonomía que permita adoptar — a lo interno de su territorio- las reglas y los acuerdos institucionales necesarios para la configuración de relaciones sociales sincronizadas con los requerimientos del añorado cambio tecnológico -y su subsecuente aumento en la productividad-. Es irrefutable que los avances tecnológicos han provocado en las últimas décadas profundos cambios sociales. También es cierto, tal como afirma Romer, que es difícil generar amplias transformaciones en las normas que rigen un entorno - ya sea público/gubernamental o corporativo - cuando no hay adecuados niveles de gobernanza. Ahora bien, ¿la cesión de territorio nacional al capital extranjero es requisito sine qua non para el impulso de la investigación tecnológica en países como Honduras? En caso afirmativo, y suponiendo que efectivamente los cambios tecnológicos dentro de estas ciudades modelo aceleren el crecimiento económico del país, ¿aplicará — ahora sí- la teoría del derrame hacia quienes no logren ingresar a estas islas de desarrollo?

Se atiende en este caso un ejemplo bastante ilustrativo de la vigencia que aún hoy mantiene la segunda tesis equivocada sobre América Latina de Stavenhagen $(1981)^{5}$, la cual plantea una crítica a las perspectivas "difusionistas", según las cuales el desarrollo de América Latina depende de la inyección de elementos modernos -en este caso, nuevas reglas para el cambio tecnológico- a los sectores arcaicos y tradicionales. Bajo tal lógica, Honduras sería un receptáculo arcaico sujeto a la consolidación de condiciones "modernas", únicamente alcanzables a través de la cesión de importantes porciones de autonomía territorial al sector privado, extranjero.

En resumen, el concepto de ciudad modelo involucra una dosis irrevocable de autoridad, la cual no puede ser legalmente derogada sin mutuo consentimiento (Sagar, 2016). Esto es muy importante si se considera que la estabilidad interna es uno de los principales atractivos que las ciudades modelo requieren para convencer a inversionistas a que den el "banderazo de salida" y comiencen a invertir en ellas. Lo anterior, ineludiblemente requiere dotar de garantías y resguardo a los capitales entrantes. Esto conlleva una superposición de los requerimientos corporativos, relacionados al resguardo de la integridad de los capitales entrantes por encima de las reivindicaciones democráticas. Continúa Sagar (2016) señalando que muchas de las críticas indican que el concepto de ciudad modelo está más orientado a asegurar la subordinación del trabajo humano al capital y garantizar la preeminencia de la maximización de utilidades por encima de la justa generación y distribución de la riqueza. Paul Romer ha esgrimido algunos argumentos para intentar sacudir al concepto de ciudad modelo de estas críticas.

$5 \quad$ Este artículo fue originalmente publicado en el periódico El Día, el 25 y 26 de junio de 1965. 
La principal línea defensiva de Romer ha sido la noción de "votar con los propios pies" -vote with one's feet-y con esto se ha afirmado que nadie estaría bajo la obligación de vivir dentro de una ciudad modelo. A través de esta supuesta decisión autónoma de ser parte de una ciudad modelo, se sostiene que habría mayor facilidad a la hora de consensuar y acatar la nueva normativa que se generen a lo interno. Continúa Romer (3 de marzo de 2010) argumentando que históricamente, la posibilidad de "votar con los propios pies" ha sido una importante fuerza para el progreso. Además, que las nuevas reglas de las ciudades modelo no serían impuestas, sino que únicamente las personas que deseen vivir y trabajar bajo estas reglas, se trasladarían hacia las mismas. Tal como se verá a continuación, esta pretensión idílica de Paul Romer de que las ZEDE funcionen únicamente con personas que hayan "votado con los pies", se derrumbó cuando el Congreso hondureño aprobó la ley de creación de las ZEDE. Esto, aunado a la falta de transparencia con que las autoridades hondureñas condujeron el proyecto, derivó en que Romer se apartara del proyecto en 2012 (Malkin, 30 de setiembre de 2012).

\section{3) CRÓNICA DE UNA APROBACIÓN FORZADA: EL DEVENIR INSTITUCIONAL DE LAS ZEDE EN HONDURAS}

La idea de las ciudades modelo ronda en las esferas de la política hondureña desde el periodo presidencial de Ricardo Maduro ${ }^{6}$; sin embargo, en ese momento no tuvo la aceptación necesaria para su implementación (Geglia, 2016). En entrevistas realizadas por Beth Geglia (2016), se menciona que existe una gran diferencia cuando este tipo de propuestas son promovidas por personas extranjeras, "especialmente cuando tienen cabello rubio y ojos azules" (p.355). Esto puede explicar el papel que han jugado en la promoción de este proyecto los ideólogos de las charter cities, entre quienes figuran personas como Patri Friedman, nieto del conocido economista Milton Friedman?

\footnotetext{
$6 \quad$ Periodo comprendido entre 2002 y 2006.

$7 \quad$ Ampliación del perfil de estos ideólogos en García (2014, pp. 53-60).
}

Tal comose explicará posteriormente, el decreto orgánico de las ZEDE contempla la creación de un Comité para la Adopción de Buenas Prácticas, el cual es la máxima autoridad de estas zonas, cuya conformación inicial se ratificó a través de un acuerdo presidencial emitido en 2014, el cual está compuesto por tan solo 4 hondureños, $y$ apenas 3 mujeres. El Comité se termina de conformar por 9 estadounidenses, 4 europeos y 3 latinoamericanos (García, 2014).

La promoción de las ciudades modelo debe enmarcarse dentro del complejo entramado sociopolítico en que se encontró Honduras luego del Golpe de Estado de 2009. La aprehensión y expulsión del ex Presidente Manuel Zelaya marcó el inicio de una nueva modalidad golpista en Latinoamérica, caracterizada por accionar en coordinación y complicidad con las instancias judiciales, $y$ así cubrir sus acciones con un manto de pseudo legalidad y constitucionalidad. Si la expulsión de Zelaya y el subsecuente nombramiento de Roberto Michelleti constituyen un flagrante golpe $y$ avasallamiento al ordenamiento jurídico hondureño, posteriormente se replicará este tipo de atropellos para abrirle camino a las ZEDE.

La incursión de las ciudades modelo en Honduras se concretó por primera vez en agosto de 2011, cuando el Congreso promulgó el Decreto Legislativo nro. 123-2011, cuyo contenido establecía la creación de las Regiones Especiales de Desarrollo (RED). No obstante, este decreto fue detenido por la Sala de lo Constitucional, la cual determinó el 2 de octubre de 2012 que "las inversiones extranjeras que se espera captar implican para el Estado de Honduras enajenar el territorio nacional, lo que expresamente prohíbe nuestra Constitución (...)", ya que su construcción significaría que “(...) se habrá privatizado el Estado de Honduras y, por tanto, habrá desaparecido como tal para dar paso a una gran corporación mercantil" (Sala declara inconstitucionales ciudades privadas en Honduras, 5 de octubre de 2012). La inconstitucionalidad de las RED terminó siendo ratificada por la Corte Suprema de Justicia (Declaran inconstitucional ciudades modelos en Honduras, 15 de agosto de 2013). 
La reacción de los sectores promotores de las ciudades modelo no se hizo esperar. Si bien, el art. 205 de la Constitución de la República le da al Congreso facultades para revisar las actuaciones judiciales, no se prevé las sanciones correspondientes. El art. constitucional 314 establece la posibilidad de sustituir a los magistrados por causas legales, pero tampoco las especifica, ante lo cual, Alexander (2015) interpreta que "bajo la lupa del análisis solo podría ser la condena por delito doloso" (p. 18).

En diciembre de 2012, el Congreso dinamitó la Sala Constitucional de la Corte Suprema de Justicia, a través de la aprobación, con 97 votos - la mayoría del Partido Nacional- de un dictamen que contenía la destitución de cuatro de sus magistrados (En sesión con inconsistencias destituyeron a magistrados, $7 \mathrm{de}$ abril de 2014). Casualmente, los cuatro magistrados separados de sus cargos, habían votado a favor de la inconstitucionalidad de las Regiones Especiales de Desarrollo (RED), y únicamente fue mantenido en su cargo el magistrado que "se opuso mediante un voto particular a la declaratoria de inconstitucionalidad de las RED, quien además fue nombrado Magistrado Presidente de la nueva Sala de lo Constitucional" (García, 2014, p. 46). Esto ha sido interpretado como una violación al principio constitucional de no subordinación entre los poderes de la República:

(...) la Sala de lo Constitucional fue defenestrada bajo lo que muchos especialistas ven como un golpe de Estado técnico, ya que el Congreso Nacional, al igual que en el 2009, interfiere en los demás Poderes del Estado, separando de su cargo a funcionarios de estos poderes en violación al Artículo $\mathrm{N}^{\circ} 4$ de la Constitución que establece que los poderes del Estado no tienen relaciones de subordinación entre sí (García, 2014, p. 46).

En su momento, la Relatora Especial de las Naciones Unidas sobre la independencia de magistrados y abogados, Gabriela Knaul, instó a las autoridades hondureñas a reconsiderar esta destitución, y expresó en comunicado con fecha del 29 de enero de 2013 que "los jueces pueden ser destituidos únicamente por razones graves de mala conducta o incompetencia, tras un procedimiento que cumpla con el debido proceso y las garantías de un juicio justo y que también prevea una revisión independiente de la decisión" (Alto Comisionado de Naciones Unidas para los Derechos Humanos, 2013). Una vez cooptada la Corte Suprema de Justicia, se allanó el camino para que fuera aprobada mediante Decreto Legislativo nro.120-2013 del 5 de septiembre de 2013, la ley que promulga la creación de las Zonas de Empleo y Desarrollo Económico (ZEDE).

\section{1) LOS PLANTEAMIENTOS DE LAS ZEDES Y SU ROCE CON LA NORMATIVA HONDUREÑA}

Según indica el art. 1 del Decreto nro. 120-2013, las ZEDE tienen personalidad jurídica propia, y están autorizadas para establecer su propia política y normativa, con el propósito de acelerar el cumplimiento de las metas del Plan de Nación y facilitar condiciones que permitan al país la inserción en los mercados mundiales bajo reglas altamente competitivas y estables. $\mathrm{El}$ art. 3 equipara a las ZEDE con los municipios del país, al indicar que gozan de autonomía funcional y administrativa, incluyendo las mismas funciones, facultades y obligaciones que tanto la Constitución de la República como las leyes le confiere a estos. El art. 8 define la jerarquía jurídica que aplicará sobre las ZEDE, mencionando a la Constitución de la República "en lo que sea aplicable". Sobre esta materia, el Ministro de Desarrollo Económico de Honduras, Arnoldo Castillo, expone:

Nosotros queremos que nuestro mismo sistema judicial, pueda verse fortalecido a través de la experiencia de otros jueces, sin nosotros trastocar la soberanía, porque al final del día, no estamos creando algo que va a venir a dictaminar algo diferente a lo que nosotros ya tenemos en nuestras leyes ${ }^{8}$ (British Broadcasting Corporation, 2018).

8 Transcripción propia. 
Lo anterior debe contrastarse con lo objetivamente establecido en el texto que regirá la materia jurídica en las ZEDE. Únicamente seis artículos de la Constitución son establecidos como de plena aplicabilidad dentro de las mismas ${ }^{9}$. Además, también existe ambigüedad en cuanto a la vigencia, aplicabilidad y obligatoriedad de respetar derechos fundamentales de rango constitucional, por ejemplo: derecho al Habeas Corpus, a la inviolabilidad de la vida, garantías sobre la dignidad humana y la integridad física, garantías contra la explotación laboral forzada, libertad de expresión y de prensa, libertad religiosa, libertades políticas (tales como la garantía de libre reunión y asociación), libertad de tránsito y garantía contra las detenciones ilegales, entre otros. Si bien, en la actualidad muchos de estos principios constitucionales son violentados por el Estado hondureño, la utilización de este argumento para defender el planteamiento jurídico de las ZEDE reviste de forma explícita la asunción de un retroceso en el resguardo de los derechos humanos, violando el principio de no regresividad.

Las ZEDE contarán con "tribunales autónomos e independientes con competencia exclusiva en las mismas, los que pueden adoptar sistemas o tradiciones jurídicas de otras partes del mundo (...)". Esto llama poderosamente la atención porque se presenta como una suplantación de la competencia del Poder Judicial en vastas áreas del país. Además, también es llamativo el art. 14, que ratifica la sujeción de las ZEDE a una jurisdicción especial, la cual operará bajo la tradición del derecho común o anglosajón (common law). Las implicaciones de este cambio de sistema jurídico deberían ser objeto de futuras aproximaciones analíticas al tema, debido a su complejidad $y$ especificidad.

El Título III del Decreto se dedica a definir la estructura político-administrativa de las ZEDE. En la figura 1 se esboza brevemente sus principales órganos y funciones.

$9 \quad$ Artículos 10,11, 12, 13, 15 y 19. Así establecido en el art. 1 del Decreto en mención. 
FIGURA 1

ESTRUCTURA ADMINISTRATIVA Y FUNCIONAL DE LAS ZEDE

SEGÚN DECRETO LEGISLATIVO 120-2013

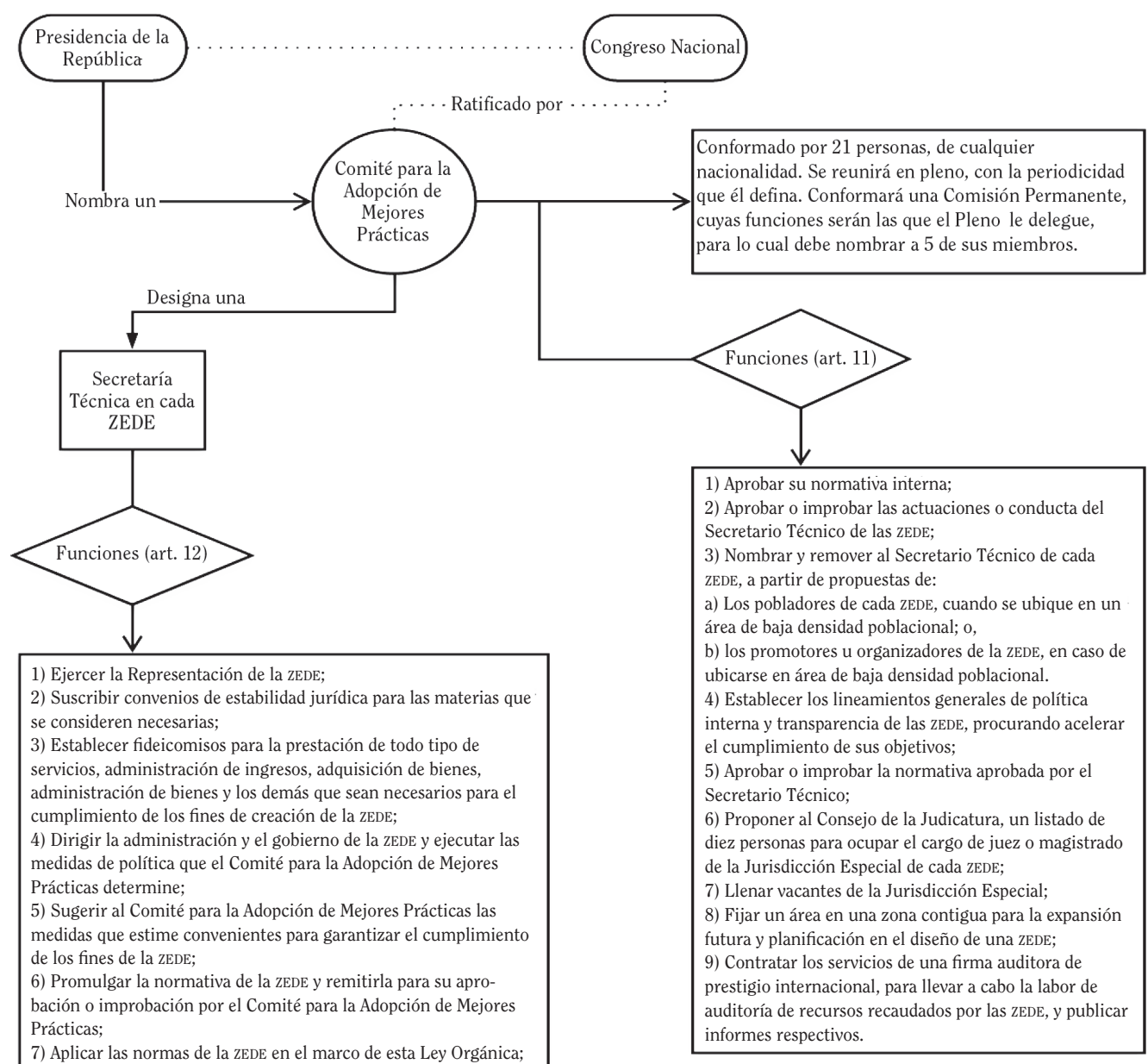

Fuente: Elaboración propia a partir del Decreto nro.120-2013.

Es plausible interpretar al Comité para la Adopción de Mejores Prácticas (CAMP) como un órgano con un alto grado de poder, elegido discrecionalmente por la Presidencia de la
República, y que en la práctica tendrá el mando sobre los demás órganos administrativos y políticos de las ZEDE. Este comité tendrá control directo sobre la designación de la Secretaría 
Técnica de cada ZEDE, quien figura como una suerte de presidente, gobernador o alcalde, $y$ que por ende se puede concebir como equivalente a las funciones tradicionales de un Poder Ejecutivo. Además, según el art. 12, está facultado para "nombrar secretarios ad hoc para que lo auxilien en la administración de la ZEDE".

Similar situación se presenta con el equivalente al Poder Judicial, cuya presencia en la Ley es un tanto difusa, ya que existe un uso extendido e impreciso del término "órganos jurisdiccionales", $y$ se concreta únicamente el nombre de uno de esos órganos, a saber, el Tribunal de Protección de los Derechos Individuales. Las personas juezas y magistradas de las ZEDE serán nombradas por el Consejo de la Judicatura del Poder Judicial de entre quienes sean propuestos en un listado remitido por el mismo CAMP. Es importante recalcar que este Comité se reserva la potestad exclusiva de conformar dicho listado, con lo cual se concluye que la administración de la justicia estará bajo control de personas afines a los integrantes del Comité.

En cuanto al manejo de las finanzas, el art. 29 establece que las ZEDE deben tener un régimen fiscal propio, $y$ se les autoriza para cobrar impuestos atendiendo los siguientes topes: a) impuesto sobre la renta a personas naturales, no mayor a $12 \%$, b) sobre la renta a personas jurídicas, no mayor a $16 \%$, c) sobre el valor agregado, no mayor a 5\%. El resto de impuestos puede ser definido por cada ZEDE, como por ejemplo, el impuesto a la propiedad de la tierra en desuso o el impuesto sobre bienes inmuebles. Además, el art. 29 también las faculta a definir y recaudar tasas por la prestación de servicios públicos o desarrollo de infraestructura. En los art. 30 y 31 se garantiza la adscripción de las ZEDE al libre comercio y la libre circulación de bienes, activos intangibles $y$ capitales. Se restringe el control cambiario y se postula que los medios de pago que circulen dentro de las ZEDE deben ser libremente convertibles. Además, las importaciones estarán libres del pago de todo impuesto o arancel.

\section{4) EL PAPEL DEL BANCO INTERAMERICANO DE} DESARROLLO (BID)

El requerimiento presupuestario para impulsar las ZEDE es bastante alto, por ello es importante revisar qué papel han jugado algunos organismos financieros internacionales. Desde julio de 2018, en el sitio web oficial del Banco Interamericano de Desarrollo (BID) se encontraba publicado el perfil del proyecto HO-L1191: Apoyo a la Atracción de Inversiones y Creación de Empleo en Honduras. La reseña del proyecto indicaba lo siguiente:

Esta operación apoyará al Gobierno de Honduras en la conceptualización y preparación de estudios técnicos y diseños para el establecimiento de Zonas de Empleo y Desarrollo Económico (zedes) que buscan: (i) el incremento de la inversión en sectores intensivos de empleo; (ii) la creación de empleos formales; $y$ (iii) la reducción del desempleo y el empleo informal. Esta operación se encuentra en una fase preliminar de preparación. Se publicará documentación adicional tan pronto esté disponible ${ }^{10}$.

Esta breve reseña fue la única información disponible en la página web del BID, sobre el posible préstamo de $\$ 20$ millones (Center for International Environmental Law-CIEL, 2017). La posibilidad de que este organismo regional financiara las operaciones iniciales de las ZEDE, alertó a organizaciones tanto hondureñas como extranjeras. La Organización Fraternal Negra de Honduras (OFRANeH) remitió una carta al señor Sr. Luis Alberto Moreno, Presidente del BID, con fecha 15 de noviembre de 2017 (OFRANEH envía carta a presidente del BID por las inconsultas "ciudades modelo", 16 de noviembre de 2017). En esta misiva, la OFRANEH alertó que el Estado de Honduras no ha efectuado

10 A mayo de 2019, el perfil del proyecto HO-L-1191 ya no se encuentra publicado en el sitio web del Banco Interamericano de Desarrollo (BID); sin embargo, evidencia de esta reseña se puede encontrar en Organización Fraternal Negra Hondureña [OFRANEH] (2017a; 2017b). 
consulta previa con el pueblo garífuna sobre las ciudades modelo, haciendo caso omiso del Convenio 169 de la Organización Internacional del Trabajo (OIT), y que además ya fue condenado en la Corte Interamericana de Derechos Humanos debido a la violación de la consulta previa durante el 2015, en los casos de las comunidades garífunas de Punta Piedra y Triunfo de la Cruz. Teniendo esto en cuenta, más otros antecedentes de análisis alrededor de las ZEDE, la OFRANEH termina su carta indicando que "es de esperar que el BID asuma apegarse a sus directivas operacionales, a la Convención Interamericana de Derechos Humanos y el Convenio 169 de la oIT".

El Centro para el Derecho Ambiental Internacional (CIEL, por sus siglas en inglés) también alzó la voz contra la posibilidad de tal financiamiento. Incluso, remitió una misiva con fecha 25 de agosto de 2017, dirigida a Mark Edward Lopes, Director Ejecutivo de los Estados Unidos ante el BID, y Alex Severens, Director de la Oficina de Resultados para el Desarrollo y Responsabilidad $^{11}$, del Departamento del Tesoro de Estados Unidos, exponiendo latentes violaciones de las disposiciones $y$ lineamientos del propio BID, concluyendo en recomendar que Estados Unidos no apoye la aprobación de tal préstamo (Alford-Jones et al., 25 de agosto de 2017).

Efectivamente, el Directorio Ejecutivo del BID ha sancionado una serie de normas (Políticas Operativas Generales y Sectoriales) que contienen lineamientos y salvaguardias de carácter ético y socioambiental que - teóricamente- son de aplicación obligatoria en todos los proyectos que financia el BID. Estas normas están orientadas a coadyuvar la identificación de potenciales impactos ambientales y sociales ocasionados por proyectos del Banco. También, establecen los estándares de acceso a información y consulta a la población de las regiones donde se generen las operaciones financiadas por el Banco.

La Política Operativa sobre Pueblos Indígenas (OP-765) es muy importante sobre el tema de marras, debido a la ya documentada amenaza existente contra el pueblo garífuna. Sus objetivos giran alrededor de a) apoyar el desarrollo con

11 Office of Development Results and Accountability, en inglés. identidad de los pueblos indígenas $y$, b) salvaguardar pueblos indígenas y sus derechos ante posibles afectaciones a raíz de proyectos financiados por el Banco (BID, 2006). La tutela de los derechos de los pueblos indígenas contenida en el objetivo b, se concreta en la Política a través de dos series de directrices: la primera interpela al Banco a que interponga sus mejores esfuerzos en apoyar el desarrollo con identidad de los pueblos indígenas; la segunda, contiene salvaguardias de acatamiento obligatorio, diseñadas para evitar o reducir los impactos negativos sobre los derechos de los pueblos indígenas.

\section{1) APOYO AL DESARROLLO CON IDENTIDAD}

Esta directriz establece el requerimiento de consultas apropiadas e informadas, según lo dispuesto por el Convenio 169 de la oIT —el cual Honduras ratificó en 1995- así como garantizar que se identifique a los pueblos potencialmente beneficiados o afectados, $y$ respetar el conocimiento tradicional, además del patrimonio cultural y natural. Dentro de los componentes del desarrollo con identidad, el BID incorpora:

(e) El fortalecimiento de los procesos de legalización y administración física de los territorios, las tierras y los recursos naturales tradicionalmente ocupados o aprovechados por los pueblos indígenas, de conformidad con las normas de derecho aplicables, así como con los objetivos de protección del medio ambiente. Estos procesos incluyen el fomento de la sostenibilidad de los usos culturales de la tierra, la promoción de la inversión en bienes comunitarios $y$ proyectos productivos en áreas indígenas, y la gestión ambiental indígena en el ámbito de sus tierras $y$ territorios (2006, p. 7).

Claramente, el anterior pasaje da cuenta de una supuesta preocupación por parte del BID de que los proyectos que financie tengan en cuenta las formas autóctonas de manejo político y administrativo de sus territorios, ante las cuales ha sido desarrollada en las últimas décadas un conjunto de normativas que pretende reducir las violaciones a dichas formas 
autóctonas. En esa línea de "normas de derecho aplicables" se encuentra el Convenio 169 de la OIT, ratificado por el Estado hondureño, de quien hasta el momento existen serias dudas sobre su cumplimiento, tal como ha sido denunciado en múltiples ocasiones por la OFRANEH y por Global Witness (2017).

\section{2) SALVAGUARDIAS EN LAS OPERACIONES DEL BANCO}

Según lo indicado en el texto de la Política OP-765, con tal de ser elegibles para financiamiento por parte del BID, las operaciones sujetas a crédito deben cumplir con las normas de derecho aplicables y acatar las salvaguardias que contiene esta política, además de ser consistentes con demás disposiciones del Banco. Lo anterior indica que el cumplimiento de las salvaguardas es elemento sine qua non para que un proyecto sea sujeto de financiamiento por parte del BID, ratificando su obligatoriedad. Estas salvaguardias se desagregan en varios rubros, entre los cuales se centrara en los referentes a impactos adversos, así como, territorios, tierra y recursos naturales.

En cuanto a los "impactos adversos", "el Banco desarrollará sus operaciones de manera de evitar o mitigar los impactos adversos directos e indirectos sobre los pueblos indígenas, sus derechos o su patrimonio, individuales o colectivos" (BID, 2006, p. 8). Se establece que el Banco deberá verificar que el proyecto a financiar realice evaluaciones para determinar posibles impactos negativos sobre la seguridad física y alimentaria, tierras, recursos, patrimonio cultural, entre otros. En caso de identificar tales impactos adversos, deberá el proyecto incluir medidas para evitarlos, lo cual conlleva procesos de consulta y negociación. La segunda salvaguardia se refiere a “Territorios, tierras y recursos naturales", e indica que las operaciones que afecten directa o indirectamente la posesión o gestión de tierras tradicionalmente ocupadas por pueblos indígenas deberán incorporar: i) mecanismos de consulta previa y ii) mecanismos para la participación de tales pueblos en la utilización, administración y conservación de los recursos en cuestión.
4.3) ROCES ENTRE LA NORMATIVA DEL BID Y LAS ZEDE

Indudablemente, la Ley Orgánica de las ZEDE presenta disposiciones que de forma irresoluble atentan contra la normativa del BID señalada anteriormente. La incompatibilidad más explícita se encuentra en el art. 43 de la Ley Orgánica de las ZEDE, el cual se perfila como una mampara de respeto a los derechos de las poblaciones indígenas, al indicar que las autoridades de las ZEDE no podrán realizar actos "que vulneren los derechos de propiedad de los pueblos indígenas $y$ afrodescendientes sobre las tierras que les hubieren sido otorgadas mediante títulos concedidos por el Gobierno de la República" (Congreso Nacional de Honduras, 2013).

Es preciso leer con detenimiento el extracto anterior de la Ley, ya que de forma sutil se deja claro que únicamente se respetará aquellas tierras con título otorgado, es decir, plenamente reconocidos por el Gobierno. Precisamente, hay antecedentes cercanos en los cuales el Estado hondureño se ha negado a reconocer la condición de indígenas a poblaciones que habitan territorios de la costa Caribe. Según la Procuraduría de la República, "ni aún en la interpretación más amplia que se haga en los criterios orientadores para definir a los pueblos indígenas, contemplados en el Convenio $169 \mathrm{u}$ otros instrumentos internacionales señalados por la CIDH, los garífunas son indígenas" (OFRANEH, 2017c). De hecho, hay casos en los cuales el reconocimiento de los títulos de propiedad de la tierra se dirime en instancia judicial, tal como sucede con el caso de Barra Vieja, cuyo caso se encuentra en la corriente de la Corte Suprema de Justicia desde el 11 de enero de 2017 (Trucchi, 2017).

También hay incongruencias dentro del mismo texto de la Ley, ya que a pesar del supuesto resguardo a los derechos de propiedad indígena indicado anteriormente, en el art. 39 se procede a declarar bajo el régimen de las ZEDE, a todas las zonas de baja densidad poblacional de los municipios ubicados en los Departamentos contiguos al Golfo de Fonseca y el Mar Caribe. Esta Ley únicamente establece la realización de una consulta cuando se trate de un área de alta densidad poblacional, a través de 
un plebiscito. La hipotética existencia de disposiciones más claras y contundentes para la protección indígena en la Ley, tampoco sería una gran garantía, teniendo en cuenta los antecedentes sobre el accionar del Estado hondureño en este tema. Global Witness (2017) publicó un exhaustivo informe sobre la persecución y asesinato de personas activistas socio ambientales de Honduras - al menos 123 asesinadas desde el Golpe de Estado de 2009- y repasando los procesos de expulsión y desalojo de familias garífunas, quienes han sido catalogadas como ocupantes ilegales. Incluso, en informe de Victoria Tauli-Corpuz, quien funge como Relatora Especial de Naciones Unidas sobre los Derechos de los Pueblos Indígenas, luego de su visita a Honduras, recalcó su preocupación sobre la amenaza de las ZEDE para esta población:

Otra gran preocupación es la propuesta creación de ciudades modelo bajo la Ley Orgánica de las Zonas de Empleo y Desarrollo Económico (...). Las ciudades modelo afectarían a 24 comunidades garífunas entre las regiones del río Sico y la bahía de Trujillo, incluyendo por desplazamientos forzosos. Se informó sobre los planes para la reubicación de 3.500 personas de la comunidad garífuna de Puerto Castilla para facilitar la construcción y ampliación de infraestructura para una ciudad modelo en Trujillo. Miembros de esa comunidad informaron que no fueron consultados sobre el proyecto $y$ se han opuesto a su reubicación, tras haber sufrido dos reasentamientos en décadas anteriores (Consejo de Derechos Humanos de la ONU, 2016, p. 13).

La OFRANEH (2015) considera que hay en marcha "una estrategia estatal para la entrega del territorio garífuna a inversionistas extranjeros, como parte del experimento neoliberal de las ciudades modelo (ZEDE) en Honduras". Debido a esto, en la misma carta suscrita por las ZEDE al Presidente del BID en el año 2017, se enumeran las anomalías que han caracterizado el avance del proyecto de las ZEDE, careciendo de procesos de consulta. Además, consideran que "en vez de cumplir con sus obligaciones de velar por sus ciudadanos, Honduras está cediendo esas obligaciones a inversionistas internacionales que se centran en aumentar las ganancias y no proveer la seguridad económica y personal" (OFRANEH envía carta a presidente del BID por las inconsultas "ciudades modelo", 16 de noviembre de 2017). Esta carta fue respondida por Mirna Liévano de Marques - representante del BID en Honduras - con oficio fechado al 15 de diciembre del $2017^{12}$, e indica que:

... a la fecha, no se han identificado los apoyos específicos que se van a dar al país en lo referente a ZEDE's; por el momento, se están analizando las barreras a la inversión que tiene Honduras y las herramientas con las cuales el país puede contar para derribar estas barreras y crear más empleo (BID, 2018).

La nota continúa indicando que todas las intervenciones del BID tienen estricto apego a sus salvaguardias sociales $y$ ambientales, $y$ que "de todas formas, el Banco agradece la información enviada en la carta adjunta y estará atento a los temas que la misma contiene". Sin duda, resulta paradójico cómo se podría compaginar el estricto apego a las salvaguardias del Banco, habiendo disposiciones en la Ley Orgánica de las ZEDE que se le contraponen rotundamente, tal como se plasmó anteriormente. Además, es llamativo que la carta sea respondida por la Representación del Banco en Honduras, a pesar de haber sido remitida originalmente a la Presidencia; también, la omisión de profundizar sobre los roces con la propia normativa del Banco.

El Gobierno de Honduras ha sido hostil a los derechos de la población garífuna (MacNeill, 2017); sus tierras son altamente apetecidas para la explotación turística (Global Witness, 2017). La carta de OFRANEH dirigida al BID, también fue copiada a la Comisión Interamericana de Derechos Humanos; sin embargo, luego de transcurrido más de un año del envío,

12 Oficio CID/CHO/2324/2017, el cual se puede consultar en el sitio web de OFRANEH. 
la OFRANEH tampoco ha recibido respuesta de ese organismo ${ }^{13}$.

\section{5) AUGURIOS SOBRE LA IMPLEMENTACIÓN DE LAS ZEDE Y LA CONFIGURACIÓN DE MECANISMOS DE DESPOJO}

El estudio de factibilidad de la primera ZEDE se encargó a personal de la Agencia de Cooperación Internacional de Corea, el cual fue entregado en 2015, junto con el plan maestro para la primera ZEDE, planteada en el Golfo de Fonseca, específicamente en los municipios de Amapala, Nacaome y Alianza del Valle (Peralta, 26 de setiembre de 2014). En estos municipios se establecería un megapuerto, un centro industrial $y$ un centro de logística, respectivamente (Corea del Sur da visto bueno para la primera ZEDE, 6 de abril de 2015). La propuesta también incorpora la conexión de esta región pacífica con el Caribe, específicamente, con Puerto Cortés, a través de una especie de canal seco (Dada, 20 de abril de 2017).

Por lo anterior, es importante prestar atención a ciertos acontecimientos recientes en el Caribe, donde empresas de capital canadiense $y$ estadounidense han comenzado a comprar numerosas hectáreas, avizorando y especulando con aumentos del valor de estas tierras a futuro. Caso ilustre el del inversionista canadiense Randy Jorgensen, quien incluso logró obtener el poder de dominio eminente - usualmente reservado para proyectos de interés público- para agilizar las expropiaciones de cara a su puerto de cruceros y yates, lo cual alcanzó gracias a su cercanía con la oligarquía hondureña (MacNeill, 2017). Lo anterior es apenas ilustrativo de una tendencia hacia el establecimiento de explotaciones turísticas de gran escala, cuyo capital proviene principalmente de inversionistas extranjeros y que tienen alto interés en expandirse hacia territorios actualmente habitados por garífunas (Trucchi, 2017).

Tal como ocurre en muchas latitudes, este tipo de mega-explotaciones turísticas tienen escaso arraigo con las poblaciones locales. Se ha identificado que la contratación de personas locales ha sido muy escasa; además,

13 Equipo ofraneh (Comunicación personal, 26 de octubre de 2018). la desatención estatal ha dejado a la población garífuna sin acceso a financiamiento para incursionar también en el turismo (MacNeill, 2017). Se aprecia que, sin necesidad de implementar aún una ZEDE, ya hay procesos de despojo en marcha. Por ello, el análisis de las ZEDE también debe considerar el surgimiento de leyes conexas que paulatinamente han ido configurando un sofisticado dispositivo jurídico de despojo y extractivismo en el seno del Estado.

Una de estas es la Ley de Fomento al Turismo, aprobada en 2017 y sumamente polémica, debido a que su art. nro. 5 exonera a hoteles y demás servicios turísticos, del pago de impuesto sobre la renta, ventas, selectivo al consumo, así como, los derechos aduaneros de importación. Incluso, el Instituto Centroamericano de Estudios Fiscales (ICEFI) recomendó la no aprobación del proyecto, por considerar "injustificado incrementar los beneficios al turismo, un sector que ha gozado por mucho tiempo de privilegios fiscales, sin evidencia de ser una fuente real de generación de empleo e inversiones de calidad" (ICEFI, 2017).

También se encuentra la nueva Ley de Minería, redactada en 2012, con el estímulo de cabildeadores canadienses y la industria minera transnacional (Gordon y Webber, 2011; Moore, 2012). Entró en vigencia en abril de 2013, y considerando la laxitud de las instituciones de fiscalización hondureñas, abrió portillos "para violaciones al dominio inalienable del Estado, la autonomía municipal, la propiedad privada, la democracia participativa, $y$ los derechos humanos, entre otras garantías básicas de un Estado de Derecho" (Palmese, 13 de julio de 2016).

El entramado de leyes conexas es aún más amplio ${ }^{14}$. En 2014, el Congreso aprobó la

$14 \quad$ El Movimiento Mesoamericano contra el Modelo Extractivo Minero (Extractivo Minero, 03 de agosto de 2016) realiza una profusa indicación de las leyes que estarían conformando ese marco legal extractivista: Ley para la Protección y la Promoción de las Inversiones, Ley para el Fortalecimiento y Efectividad de la Política de Seguridad (Ley Antiterrorista), Ley para la Intervención de las Comunicaciones Privadas, Ley para la generación de energía hidroeléctrica, Ley de la Policía Militar y el Orden Público, Ley para la Reconversión de la Deuda Pública. 
Ley de Empleo por Hora, valioso instrumento para la precarización laboral (Trucchi, 26 de julio de 2016). Además, la utilización de la Ley de Asociación Público Privada también ha estado envuelta en polémica, en casos como la construcción del denominado Corredor Turístico de Honduras (Asociación para una Sociedad más Justa, 2018). En resumen, las ZEDE deben ser enmarcadas analíticamente dentro de dicho entramado legal de fuerte impronta neoliberal $y$ extractivista, que articulan un dispositivo de despojo de gran amplitud y alcance. Paulatinamente, se ha configurado en Honduras un escenario difícilmente mejorable para los procesos de extracción de recursos y acumulación de capitales. Quizás, un caso ilustre de la fase contemporánea del capitalismo latinoamericano.

\section{6) APERTURAS FINALES}

El retrato de Honduras durante los últimos diez años, denota la existencia de formas de colusión entre élites económicas y actores político-institucionales, que ha permitido complejos procesos de extracción de fondos públi$\cos y$ su subsecuente redireccionamiento hacia arcas privadas (Chayes, 2017). Lo anterior ha conllevado a conceptualizar al Estado hondureño como un "nicho de acumulación", lo cual implica que, si bien las riquezas sujetas a procesos de extracción y despojo terminan siendo acumuladas en arcas privadas, de previo a ello se requiere implementar estrategias $y$ mecanismos que permitieran evadir los - mayores o menores - controles legales, y los eventuales mecanismos de fiscalización ciudadana. Es decir, dentro de los procesos de despojo y sus correspondientes etapas, el tránsito por las instancias estatales no se puede eximir, derivando en que tenga que disputarse allí el éxito o fracaso de tales procesos de extracción y explotación ilegítima de riquezas.

Ahora bien, con lo aquí expuesto se pretende instar a reflexionar si los planteamientos de las ZEDE - y demás leyes conexas - podrían implicar una paulatina transición del Estado hondureño desde su faceta actual de "nicho de acumulación" hacia una configuración como "medio tangencial de acumulación". Esto último se entenderá como una faceta en la cual se reduce a mínimos nunca antes vistos, la capacidad de control y la fiscalización del aparato estatal hondureño sobre su territorio. Es decir, que los procesos de corrupción, así como, extracción y explotación ilegítima de riquezas, ya ni siquiera deberán preocuparse por evadir los posibles mecanismos de control estatal y ciudadano, sino que estarían operando en espacios con autonomía jurídica prácticamente total.

¿Qué implica esto, en el marco de la teoría del Estado contemporánea? Si bien, el paradigma hegemónico neoliberal propugna la reducción de la presencia estatal en la vida socioeconómica, tampoco proclama su desaparición ni la relega a niveles tan exiguos como lo estipulado por el marco orgánico de las ZEDE. Esto trastoca las formas tradicionales de malversación y despojo de recursos públicos que ha atendido Latinoamérica recientemente, ya que si bien, usualmente culminan extrayendo riquezas hacia arcas privadas, previo a ello se debió afinar los mecanismos que permitieran tal evacuación de recursos públicos, lo cual se concreta a través de sobornos, estratagemas jurídicas, paraísos fiscales, etc.

La hipótesis sobre la especificidad de las ZEDE como mecanismo de despojo sin parangón en Latinoamérica, requiere más investigación para ser acogida plenamente. Además, futuros abordajes también deberían considerar profundizar el análisis sobre el engarzamiento de variados marcos normativos recientemente aprobados o actualizados en Honduras - leyes conexas-, y que en su conjunto configuran complejos dispositivos jurídicos para el despojo y acaparamiento de recursos. Estos fenómenos de parcelación territorial, jurídica y administrativa-institucional, en un contexto de creciente expulsión de personas centroamericanas hacia otras latitudes, pone sobre la palestra el rol de los estados centroamericanos como mecanismos de sometimiento, explotación y expulsión, por encima de la integración.

\section{REFERENCIAS}

Alexander, E. (2015). ¿Independencia judicial en Honduras? Balance de la situación y principales desafíos. Fundación Friedrich Ebert Stiftung. 
Alford-Jones, K., Carasik, L. y Spring, K. (25 de agosto de 2017). Carta dirigida a Mark Lopes y Alex Severens. Concerns about HO-L1191: Support to the Creation of Employment and Economic Development Zones (ZEDEs). http://www. ciel.org/wp-content/uploads/2017/11/ Memo_Concern_IDB_Honduran_ZEDE_ Project.pdf

Alto Comisionado de Naciones Unidas para los Derechos Humanos. (2013). Grave atentado a la democracia en Honduras la destitución de magistrados de la Sala Constitucional. https://newsarchive.ohchr.org/SP/ NewsEvents/Pages/DisplayNews. aspx?NewsID=12958\&LangID=S

Arias, R., Sánchez, L., Vargas, L., Agüero, O. y Quesada, Y. (2016). Identificación y definición de las Zonas Especiales de Desarrollo (ZED) en Costa Rica. Serie de Divulgación Económica, IICE-44.

Asociación para una Sociedad más Justa [ASJ]. (2018). Análisis de la Estructuración, Contratación y Ejecución del Contrato de Concesión del Corredor Turístico de Honduras. http://asjhonduras.com/ webhn/analisis-de-la-estructuracioncontratacion-y-ejecucion-del-contratode-concesion-del-corredor-turistico/

Banco Interamericano de Desarrollo [BID]. (2006). Politica Operativa sobre Pueblos Indigenas (OP-765). http://idbdocs.iadb.org/wsdocs/getdocument. aspx?docnum $=1442306$

Banco Interamericano de Desarrollo [BID]. (2018). HO-l1191: Apoyo a la Atracción de Inversiones y Creación de Empleo en Honduras. https://www.iadb.org/es/project/HO-L1191

Barahona, M. (2018). Del pacto bipartidista al pacto de impunidad: ingobernabilidad, corrupción y crisis general en Honduras. En C. Villacorta y E. De Gori. (Eds), Golpe electoral y crisis politica en Honduras (pp. 37- 46). Consejo Latinoamericano de Ciencias Sociales (CLACSO).

British Broadcasting Corporation (Productor). (2018). Las ZEDE, el polémico proyecto de "ciudades privadas" de Honduras [BвC News Mundo]. https://www.youtube.com/ watch? v=ZU3QkNT_Hgo

Center for International Environmental Law [CIEL]. (2017). Should the Inter-American Development Bank Fund Honduras to Implement Controversial Special Economic Zones? https://www.ciel.org/ wp-content/uploads/2017/12/zEDEanalysis.pdf

Chayes, S. (2017). When corruption is the operating system: the case of Honduras. Informe publicado por Carnegie Endowment for International Peace. https://carnegieendowment.org/files/ Chayes_Corruption_Final_updated.pdf

Congreso Nacional de Honduras. (2013). Decreto Legislativo nro. 120-2013, Ley Orgánica de las Zonas de Empleo y Desarrollo Económico (ZEDE). https:// www.tsc.gob.hn/biblioteca/index.php/ leyes/503-ley-organica-de-las-zonas-deempleo-y-desarrollo-economico-zede

Consejo de Derechos Humanos de la onu. (2016). Informe de la Relatora Especial sobre los derechos de los pueblos indigenas sobre su visita a Honduras. http:// unsr.vtaulicorpuz.org/site/index.php/es/ documentos/country-reports/148-reporthonduras

Corea del Sur da visto bueno para la primera ZEDE. (6 de abril de 2015). La Prensa. https://www.laprensa.hn/inicio/828314-417/corea-del-sur-da-vistobueno-para-construcci\%C3\%B3n-de-zede

Dada, C. (20 de abril de 2017). Honduras y su experimento libertario en el golfo de Fonseca. El Faro. https://elfaro. net/es/201704/centroamerica/20283/ Honduras-y-su-experimento-libertarioen-el-golfo-de-Fonseca.htm

Declaran inconstitucional ciudades modelos en Honduras. (15 de agosto de 2013). La Prensa. https://www.laprensa.hn/honduras/tegucigalpa/330285-98/declaraninconstitucional ciudades-modelos-enhonduras

Dixin, X. (1981). China's Special Economic Zones. Beijing Review, (50). http://www. 
bjreview.com.cn/nation/txt/2009-05/26/ content_197576.htm

En sesión con inconsistencias destituyeron a magistrados. (7 de abril de 2014). El Heraldo. https://www.elheraldo.hn/alfrente/565722-209/en-sesion-con-inconsistencias-destituyeron-a-magistrados

Extractivo Minero. (03 de agosto de 2016). El modelo «extractivista» en Honduras. https://movimientom4.org/2016/08/ el-modelo-extractivista-en-honduras/

Fernández, B. (14 de julio de 2012). Partitioning Honduras: The advent of charter cities. Al Jazeera. https:// www.aljazeera.com/indepth/opinion/2012/07/2012711121224166933.html

García, F. (2014). Las ciudades burbuja: Zonas de Empleo y Desarrollo Económico ZEDE en Honduras. Análisis Político-Jurídico de la Legislación e las ZEDE. Fundación Friedrich Ebert Stiftung.

Geglia, B. (2016). Honduras: Reinventing the Enclave. NACLA report on the Americas. https://www.tandfonline.com/ doi/abs/10.1080/10714839.2016.1258278? needAccess $=$ true

Global Witness. (2017). Honduras: el país más peligroso para defender el planeta. https://www.globalwitness.org/en/ campaigns/environmental-activists/ honduras-el-pa\%C3\%ADs-m\%C3\%A1speligroso-del-mundo-para-el-activismoambiental/

Gordon, T. y Webber, J. R. (2011). Canada and the Honduran coup. Bulletin of Latin American Research, 30 (3), 328-243.

Instituto Centroamericano de Estudios Fiscales [ICEFI]. (2017). Comunicado de prensa HN-05-2017: Honduras: Icefi recomienda al Congreso Nacional no aprobar la propuesta de Ley de Fomento al Turismo. http://www.icefi.org/sites/default/files/ hn-05-2017comunicado_icefi_rechazo_ley_de_fomento_al_turismo_24_ jul_20172.pdf

Kee-Cheok, C. y Kim-Leng, G. (2013). Hong Kong as charter city prototype-When concept meets reality. Cities (35), 100-103.
Laínez, V. y Meza, V. (1973). El enclave bananero en Honduras. Nueva Sociedad (6), 21- 43.

MacNeill, T. (2017). Development as Imperialism: Power and the Perpetuation of Poverty in Afro-Indigenous Communities of Coastal Honduras. Humanity \& Society (41), 210- 234.

Malkin, E. (30 de setiembre de 2012). Plan for Charter City to Fight Honduras Poverty Loses Its Initiator. New York Times. https://www.nytimes.com/2012/10/01/ world/americas/charter-city-plan-tofight- honduras-poverty-loses-initiator. html?_r $=0$

Moore, J. (2012). Canada's mining industry \& corporate social responsibility. The Community Networks. https://communitynetworks.wordpress.com/2012/10/03/ canadas-mining-industry-corporatesocial-responsibility-part-l/

Núñez, S., Herrera, F. y Flores, M. (s.f). Extractivismo y resistencia comunitaria en Honduras. https://www.tni.org/files/ publicationdownloads/extractivismo_y_ resistencia_comunitaria_en_honduras_0.pdf

OFRANEH envía carta a presidente del BID por las inconsultas "ciudades modelo". (16 de noviembre de 2017). Criterio. https:// criterio.hn/2017/11/16/ofraneh-enviacarta-presidente-del-bid-las-inconsultasciudades-modelo/

Organización Fraternal Negra Hondureña [OFRANeH]. (2015). El atentado contra Vidal Leiva, y la intervención canadiense en la bahía de Trujillo. https://ofraneh. wordpress.com/2015/12/03/el-atentadocontra-vidal-leiva-y-la-intervencioncanadiense-en-la-bahia-de-trujillo/

Organización Fraternal Negra Hondureña [OFRANEH]. (2017a). Carta al BID en relación a su proyecto de apoyo a las inconsultas "ciudades modelo" (ZEDE). https:// ofraneh.wordpress.com/2017/11/16/carta-al-bid-en-relacion-a-su-proyecto-deapoyo-a-las-inconsultas-ciudades-modelo-zede/

Organización Fraternal Negra Hondureña [OFRANEH]. (2017b). Honduras: El BID y su 
apoyo inconsulto al proyecto neocolonial de las ZEDE. https://www.alainet.org/es/ articulo/186916.

Organización Fraternal Negra Hondureña [OFraneh]. (2017c). Persiste el Indura Hilton en despojar a la comunidad Garifuna de Barra Vieja. https://ofraneh. wordpress.com/2017/01/26/persiste-elindura-hilton-en-despojar-a-la-comunidad-garifuna-de-barra-vieja/

Palmese, L. (13 de julio de 2016). El gobierno hondureño invita a las mineras, pero la casa sigue en desorden [Mensaje de un blog]. https://dplfblog.com/2016/07/13/elgobierno-hondureno-invita-a-las-mineras-pero-la-casa-sigue-en-desorden/

Peralta, A. (26 de setiembre de 2014). Revelan infraestructura necesaria para construir las ZEDE's en Honduras. PanAm Post. https://es.panampost.com/adriana-peralta/2014/09/24/revelan-infraestructuranecesaria-para-construir-las-zedes-enhonduras/?cn-reloaded $=1$

Robinson, W. (2012). Latin America in the New Global Capitalism. NACLA report on the Americas. https://nacla.org/sites/default/ files/A04502015_6.pdf

Romer, P. (1990). Endogenous Technological Change. The Journal of Political Economy, 98 (5), 71-102.

Romer, P. (27 de enero de 2010). For richer, for poorer. Prospect. http://www.prospectmagazine.co.uk/magazine/for-richer-forpoorer

Romer, P. (3 de marzo de 2010). Technologies, Rules and Progress: The Case for Charter Cities. Center for Global Development. https://www.cgdev.org/publication/technologies-rules-and-progress-case-charter-cities

Sagar, R. (2016). Are Charter Cities Legitimate? Journal of Political Philosophy (24), 509-529.

Sala declara inconstitucionales ciudades privadas en Honduras. (5 de octubre de 2012).
La Nación. https://www.nacion.com/ el-mundo/sala-declarainconstitucionales-ciudades-privadas-en-honduras/ ZZEFWSOGDVBDRMPI5NXPPAEI44/story/

Sosa, E. (2017). Transformaciones en las élites económicas, Estado y el proceso de democratización y desdemocratización: el caso de Honduras, 1990-2017. Anuario de Estudios Centroamericanos (43), 125-148.

Special economic zones: Political priority, economic gamble. (4 de abril de 2015). The Economist. https://www.economist.com/ finance-and-economics/2015/04/04/political-priority-economic-gamble

Stavenhagen, R. (1981). Sociología y Subdesarrollo. Nuestro Tiempo, 15-84.

Trucchi, G. (2017). Expolio de los territorios garífunas en Honduras: impactos del extractivismo y la expansión turística. Informe de investigación publicado por Alba Sud. http://www.albasud.org/publ/ docs/78.pdf

Trucchi, G. (26 de julio de 2016). Ley de Empleo por Hora: uso y abuso en el sector servicios y turismo. Alba Sud. http://www. albasud.org/noticia/es/897/ley-deempleo-por-hora-uso-y-abuso-en-el-sector-servicios-y-turismo

Villena, S. (2017). Siete tesis equivocadas sobre América Latina: Notas sobre la actualidad de la categoría de "colonialismo interno”. Ponencia inédita.

Waxenecker, H. (2016). Honduras: ¿Redes indebidas de poder, impunidad y enriquecimiento? Un bosquejo de una realidad compleja. Informe de investigación publicado por Heinrich Boll Stiftung. https://mx.boell.org/sites/default/files/ honduras_21-07-2016_final.pdf

Fecha de ingreso: 17/01/2019 Fecha de aprobación: 07/10/2019 